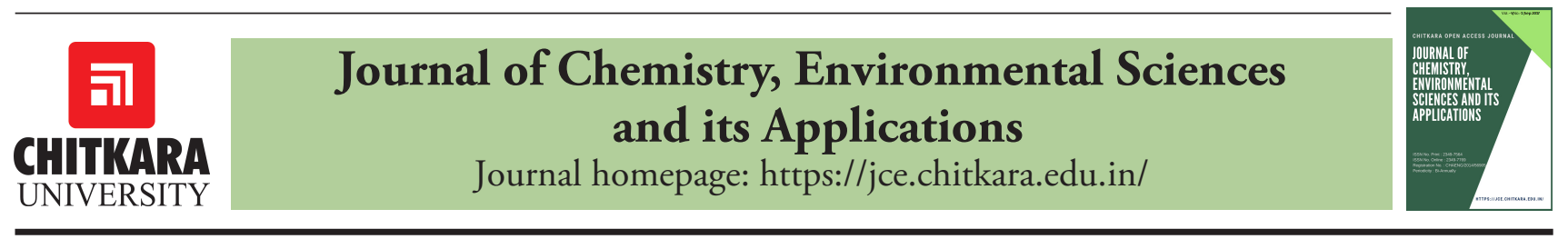

\title{
Applied Perspectives of Environmental Psychology and Wellbeing
}

\author{
Dr Varsha Sharma \\ Assistant Professor, Department of Psychology, University College of Social Sciences \& Humanities, Mohanlal Sukhadia \\ University, Udaipur, 313 001, Rajasthan
}

Email: imvarshajoshi@gmail.com

\section{ARTICLE INFORMATION}

Received: 16 July 2017

Revised: 27 July 2017

Accepted: 09 August 2017

Published Online: September 6, 2017

Keywords:

Environment, Psychology, Wellbeing, Health Promoting life style

DOI: https://doi.org/10.15415/jce.2017.41006

\begin{abstract}
Environment is a boon given to each and every living organism on the earth. Being with the nature is always a rich source of mental peace and wellbeing. Connectivity with the nature always gives a sense of being blessed by the Almighty God; it leads to enhance the sense of fully functioning self of the individual as well. Environmental Psychology is an interdisciplinary field which focuses on the application of interaction with environment on the mental, physical, social and spiritual wellbeing. Several research studies have indicated that involvement with natural surroundings is beneficial for the enhancement of overall wellbeing of the society in general and of individuals in particular. Nature is significantly important for the mental health as it helps to reduce the level of stress, irritation, anxiety, aggression, cardiovascular disease etc. The need of the hour is to encourage the health promoting lifestyle which ensures the interaction with the environment in the form of morning walks, meditation, mindfulness, yoga, breathing exercises, cycling, skipping, playing outdoor games etc.
\end{abstract}

\section{Introduction}

Life has evolved in the lap of Mother Nature. In ancient times there was a perfect balance between the environment and human beings, our ancestors used to do the daily life activities by interacting with the nature. Environment is a rich source of wellbeing and positive energy. Whenever we are in nature we feel blessed and secured. But due to the technological advancement we are now away from our loving and caring mother nature. God has created the nature so beautifully that it reminds us the love of our omnipotent almighty God. As we are now compelled to live in the artificial environment, we are deprived of this positive energy. Due to excessive deprivation of nature we get frustrated and that leads to aggressive, irritation, headaches, low mental health and ultimately disturbed overall wellbeing. Wellbeing shows the satisfaction of any individual in different sphere or areas of life where he feels happiness and full of life. Wellbeing indicates all over satisfaction from life. Environmental psychology is a science that studies connection between environment and mental health of the individuals. It states that humans have positive reactions to the natural environment. Now as the lifestyles have changed significantly we have started losing the connectivity with nature. Due to urbanization the connection between nature and humans is becoming very limited. All of us are forced to work in artificially build environment, drive on heavy traffic roads, walk on over crowded streets and many more all of these are the source of stress and threats to our wellbeing, they result into disturbed mental health, irritation, anxiety, restlessness, depression, health related ailments etc. A number of studies have been conducted in the recent past. Researchers were focused to find out the relationship between nature and wellbeing. Review of literature indicated that urbanization is a potential cause of deprivation from natural surroundings.

\section{Application of Environmental Psychology}

Environment psychology states that the natural surroundings are the good source of positive energy. It provides a platform to be a fully functioning individual. According to the subject spending time in natural environment has more positive effects as compare to artificial environment. It is helpful in reducing stress, improving overall wellbeing of the individual. The city environment has negative impact on wellbeing of the individuals. Such natural deprivation can lead to anxiety disorders, mood disorders, schizophrenia; Aggressive behaviour etc. studies conducted on nature connectedness tendencies indicated that gardening habit 
can enhance the sense of wellbeing and it was noted that working in the garden on regular basis is beneficial to reduce stress. Some studies have focused on the ancient practice of forest bathing. This activity helps to feel the freshness of nature and helps to reduce pulse rate and urinary adrenaline. It also helps in reducing anxiety, depression, confusion and fatigue state. The tendency to be with nature is also beneficial for the better treatment of cardio vascular disease. Research studies have proved that simple nature walk is helpful in reducing stress and severity of cardiovascular disease. Studies indicated the importance of green exercise, yoga meditation in amidst of natural surroundings. Such activities are more effective in natural settings.

Being with nature is also helpful for the memory span increment. It also helps to increase self esteem, decision making, positive self concept, effective emotional expression etc. Nature can be our best friend or true companion which will never leave us. The need is to be with nature and ensure the availability of sustainable natural surroundings. All of us should be motivated to include nature connectedness in our day today lifestyle.

\section{Conclusion}

It can be concluded that everyone should follow such lifestyle which includes at least 30 minutes interaction with natural surroundings, it can be in any form whether morning walk, simple exercises like yoga, and breathing exercises, meditation, suryanamaskar, etc. Nature is a direct source of positive energy that gives mental peace and is helpful in enhancement of overall health including physical, mental, social, spiritual wellbeing of the individual.

\section{References}

Barton J. \& Pretty J. (2010). "What is the best dose of nature and green exercise for improving mental health? A multi study analysis Environment Sciences Technology" 2010 May (10) 3947-55.doi.101021

Barton J. et. al., (2012). Exercise, Nature and Socially interactive based initiatives improve mood and self esteem in the clinical population. Perspect public Health 2012 Mar 132 (2). 89-96.

Barton J. Griffin M., Prettey J. (2010). Exercise-nature-and socially interactive based initiatives improve mood and self esteem in the clinical population percept public health.

Berman M G et. al., (2012). Interacting with nature improves cognition and affect for individuals with expression Journal of affect disorder 2012 Nov. 140(3) 300-5. doi: 10:1016/j.jad 2012.3.12 E. Pub 2012 Mar 31.

Jain Uday (2010). Quality of life \& Worldwide views on Environment Relationship. Journal of Wellbeing Vol. 4/Nov. 2/ July 2010.

Li Q et. al., (2016). Effect of forest bathing on cardio vascular and metabolic parameters in middle aged males. Evid based complement altemat med 2016.2016. 2587381. doi 101155/2016/2587381. E Pub 2016 Jul 14.

Li Q. et. al., (2011). Acute effects of walking in forest environments on cardiovascular and metabolic parameters. European Journal of applied physical (2011) Nov. 111(1): 2845-53 doi: 10.1007/S00421011-1918 Z. EPub 2011. Mar 23. Singh, S. et al. (2010) Marital adjustment \& psychological wellbeing Among females of early \& late marriage. Journal of wellbeing.Vol. - 4/Nov. 2/July 2010.

Van Den Berg \& Custers M.H. (2011). Gardening promotes neuroendocrine and affective restoration from stress. "Health Psychology, 2011 Jan; 16(1): 3-11 doi: 10.11 77/135910365577. E pub 2010 Jun. 